\title{
Evaluation of color intensity enhanced by paprika as feed additive in goldfish and koi carp using computer-assisted image analysis
}

\author{
Csaba HANCZ, ${ }^{1}$ István MAGYARY,,${ }^{1}$ Tamás MOLNÁR, ${ }^{1}$ Shoh SATO, ${ }^{3}$ Péter HORN ${ }^{1}$ AND \\ NOBUHIKO TANIGUCHI ${ }^{2 *}$ \\ ${ }^{1}$ University of Kaposvár, Faculty of Animal Science, Department of Small Animal Production, \\ H-7400 Kaposvár, Hungary, ${ }^{2}$ Tohoku University, Laboratory of Applied Population Genetics, \\ Graduate School of Agriculture, Sendai, Miyagi 981-8555 and ${ }^{3}$ Niigata Prefectural Inland \\ Water Fisheries Experiment Station, Nagaoka, Niigata 940-1137, Japan
}

\begin{abstract}
Body color intensity of red-colored koi carp Cyprinus carpio and goldfish Carassius auratus auratus varieties were measured to evaluate the effect of paprika used as a feed additive. Digital photos of the experimental fish were processed and analyzed by using special software. The red, green and blue (RGB) values of images were recorded and grayscale values of $R, G$ and $B$ were analyzed. The RGB values seem to play different roles in the development of the visible 'redness' of the two species. In most cases the B values decreased continuously during the administration of the paprika as a carotenoid feed additive, which seemed to have no effect on this process. The G values remained unchanged or decreased slightly as redness increased due to paprika feeding. The $R$ values had a tendency to increase due to paprika feeding but significant differences can be expected only after 4 weeks at the feeding conditions applied here. Both the initial rate of redness and genetic background are thought to influence the rate of red color intensity change, which was observed to be different in the two fish species studied here.
\end{abstract}

KEY WORDS: computer-assisted analysis, digital imaging, goldfish, nishikigoi, ornamental koi carp, paprika, red color intensity.

\section{INTRODUCTION}

The popularity of Japanese ornamental carp, Cyprinus carpio ('koi carp' or 'nishikigoi') and the Chinese goldfish, Carassius auratus auratus is growing worldwide due to the increasing number of hobbyists (e.g. garden pond keepers). Consequently, the demand for more attractive and valuable koi carp and goldfish varieties is increasing as well. However, these high-quality fish are not produced efficiently. Selective breeding of higher quality koi carp and goldfish is based mainly on traditional and empiric ways, lacking a standard evaluation system. A quantitative evaluation system should be set up in order to make the selective breeding on body color of koi carp and goldfish more efficient. The application of up-to-date digital photography and computer-assisted image processing and analysis may become a powerful tool for selective

${ }^{*}$ Corresponding author: Tel: 81-22-717-8740.

Fax: 81-22-717-8743. Email: nobuhiko@bios.tohoku.ac.jp

Received 24 September 2002. Accepted 18 July 2003. breeding of ornamental fish, including the appreciation of ornamental carp and gold fish.

The beautiful yellow, orange and red colors found in the skin of ornamental fish are the result of a group of carotenoid pigments. Fish, in the same way as other animals, must ingest carotenoids as precursors for vitamin A, as well as depositing pigments. Because animals are incapable of a de novo synthesis of carotenoids, these compounds must be supplied in the diet. Fish fall into three broad groups according to their ability to transform these pigments: (i) those that can make no changes and can only deposit the pigment; (ii) those that can make some changes including a conversion of $\beta$-carotene to astaxanthin; and (iii) those that can make astaxanthin but not from $\beta$-carotene. ${ }^{1}$

According to Katayama et al., goldfish and fancy red carp (koi carp) can convert lutein, zeaxantin (or intermediate) to astaxanthin but $\beta$-carotene is not an efficient precursor of astaxanthin. ${ }^{2}$ Astaxanthin can be stored directly in these species. Carotenoids are commonly used feed additives for goldfish, 
carp and other species. There are synthetically produced $\beta$-carotene, canthaxanthin, and astaxanthin or natural materials such as carrot, palm oil, marigold, Dunaliella, Spirulina, krill and crustacean meals. Recently red paprika, containing high amounts of capsanthin, has been attracting much attention also in aquacultural circles. Tsushima et al. investigated the accumulation of pigments from paprika in the integument of goldfish exposed to direct and indirect sunlight. ${ }^{3}$ Considering the results of Morimoto et al. on paprika-fed fancy red carp, ${ }^{4}$ Tsushima et al. drew the following conclusions: ${ }^{3}$ (i) paprika was effective for pigmentation of goldfish and fancy red carp and its effect was increased remarkably by sunlight; and (ii) the goldfish and the fancy carp accumulated capsanthin and oxidatively metabolized capsanthin to 4-ketocapsanthin.

The application of computer-assisted image analysis in ornamental fish breeding has been very limited so far. Taniguchi et al. reported on the application of an image analyzer (Shimadzu, Tokyo, Japan) for measuring the area of red and black spots in ploidy-manipulated fancy carp. ${ }^{5}$ The different colors recognized with normal visual activity are the result of a mixture of light of different wavelengths. It has been determined that certain wavelengths of red $(R)$, green $(G)$ and blue (B), when combined with each other in various proportions (intensities) will produce a wider range of colors than any other combinations of the three colors. These colors are thus referred as the primary colors of light. ${ }^{6}$ The 'true color' digital images consist of 24 bits ( 3 bytes): 1 byte red, 1 byte green, 1 byte blue (RGB) in each pixel (dot). The color of a certain pixel is determined by the so-called 'grayscale' values (256 shades, 8 bits) of R, G and B.

In the present study we measured the effects of paprika on the red color intensity of goldfish and ornamental koi carp using standard light conditions, digital photos and a special software in computer-assisted image analysis.

\section{MATERIALS AND METHODS}

Kohaku koi carp (red markings on a white background) and red telescope goldfish were used during the experiments. Thirteen kohaku koi carp and 35 goldfish were kept per treatment unit (aerated plastic tank of $150 \mathrm{~L}$, working in recirculation system). Experimental fish in both species were randomly sampled from larger populations. The two control groups were fed on common carp feed fabricated by Feed Full (Hernad, Hungary) containing $28 \%$ protein and $5.4 \mathrm{mg} / \mathrm{kg}$ carotenoid. The two experimental groups were fed on color-enhanced feed containing paprika powder (6.38\% mass $/ \mathrm{mass}), 28 \%$ protein and $171 \mathrm{mg} / \mathrm{kg}$ carotenoid.

The daily amount of feed was $3 \%$ of the total body weight. Feed consumption was measured and calculated for the whole investigation period. Fish were weighed at the taking of digital photos. Average initial weights of koi carp and goldfish were $69.1 \mathrm{~g}$ and $2.1 \mathrm{~g}$, respectively. The duration of the experiment was 62 days for koi carp and 27 days for goldfish. Fish in the tanks were exposed to natural photoperiod.

Digital photos were taken for computer-assisted image analysis under standard light conditions (lamp type: Philips TL-D Special 90; two tubes of F95, color temperature $5300^{\circ} \mathrm{K}$; one tube of F33, color temperature $4100^{\circ} \mathrm{K}$ ), by using a digital camera (Olympus C-2000 Zoom; Olympus Optical, Tokyo, Japan). Photos of koi carp were taken on days 0,37 and 62; photos of goldfish were taken on days 0 and 27, when 10 randomly chosen fish per group were photographed. Digital photos were processed using special software for koi carp appreciation designed and created with the contribution of the University of Kaposvar and Pictron in Hungary. Grayscale values (0-255) of R, G and B components of the RGB scale were measured within a $30 \times 30$ pixel area of the red-colored dorsal body surface.

The experimental data were analyzed statistically using SPSS 8.0 program (SPSS, Chicago, IL, USA). The effect of feeding time on RGB values was evaluated by one-way ANOVA, control and paprika separately, where means were compared by the Student-Neuman-Keuls range test. Differences between the control and paprika-added group means at the same photographing time were compared by independent sample $t$-tests.

\section{RESULTS}

The control group of koi carp had a $0.50 \mathrm{~g}$ daily gain and $2.1 \mathrm{~g} / \mathrm{g}$ of feed conversion ratio. Corresponding values of the paprika-fed group were $0.26 \mathrm{~g}$ and $4.2 \mathrm{~g} / \mathrm{g}$. Goldfish had a low rate of weight gain: $0.07 \mathrm{~g} /$ day (control group) and $0.09 \mathrm{~g} /$ day ('paprika' group), respectively. Feed conversion was $1.94 \mathrm{~g} / \mathrm{g}$ for the control and $2.28 \mathrm{~g} / \mathrm{g}$ for the paprika group.

The difference in red color intensity between the control and paprika groups was clearly visible to the naked eye in goldfish after 1 month and in koi carp after 2 months of paprika feeding. The initially less reddish goldfish had a more rapid and apparent improvement in red color intensity in the paprika group. 
Table 1 Changes of RGB grayscale values in koi carp

\begin{tabular}{lccrrrr}
\hline \multirow{2}{*}{ Sampling } & & \multicolumn{2}{c}{ Control } & & \multicolumn{2}{c}{ Paprika } \\
\cline { 3 - 4 } & RGB & Mean & SD & & Mean & SD \\
\hline & R & 213.2 & 14.1 & & $206.1^{\mathrm{a}}$ & 8.9 \\
& $\mathrm{G}$ & 69.1 & 20.6 & & 60.7 & 11.8 \\
& $\mathrm{~B}$ & $19.1^{\mathrm{a}}$ & 5.4 & & $18.0^{\mathrm{a}}$ & 8.4 \\
& $\mathrm{R}$ & 216.4 & 12.6 & & $206.9^{\mathrm{a}}$ & 10.2 \\
& $\mathrm{G}$ & 76.2 & 11.7 & & 69.4 & 13.9 \\
& $\mathrm{~B}$ & $7.7^{\mathrm{b}}$ & 4.1 & & $12.5^{\mathrm{a}}$ & 7.5 \\
& $\mathrm{R}$ & 215.0 & 9.2 & & $222.2^{\mathrm{b}}$ & 7.4 \\
& $\mathrm{G}$ & $86.4^{*}$ & 12.8 & & $62.0^{*}$ & 15.0 \\
& $\mathrm{~B}$ & $0.8^{\mathrm{c}}$ & 1.2 & & $2.0^{\mathrm{b}}$ & 1.8 \\
& & & & & \\
\hline
\end{tabular}

$n=10$ randomly chosen fish per experimental unit.

$\mathrm{R}$, red; G, green; B, blue (grayscale values).

${ }^{*} P<0.05$ (control vs paprika, $t$-test); ${ }^{\text {ab, }, \mathrm{c}} P<0.05$ (comparison of RGB means of samplings using ANOVA).

Results detected in the comparison of RGB values of each sampling of koi carp within control and paprika groups using one-way ANOVA are as follows. A significant decrease in B values was found in the control group of koi carp at the second and third samplings when compared to $B$ values of day 0 , whereas B values in the paprika group decreased significantly only at the third sampling. Significantly higher $\mathrm{R}$ values were found in the paprika group of koi carp at the third sampling. Changes of $\mathrm{G}$ values in both groups at all samplings were not significant. Results derived from the comparison of control and paprika groups of koi carp using independent sample $t$-tests showed significantly lower $\mathrm{G}$ values for the paprika group at the third sampling (Table 1).

Results achieved with the comparison of RGB values of each sampling of goldfish within control and paprika groups are as follows. Significantly lower $\mathrm{R}$ values were detected in the control group at second sampling. In contrast, the $\mathrm{R}$ values in the paprika group increased somewhat (non-significantly). Significantly lower B values could be found in the paprika group at second sampling. Results derived from the comparison of control and paprika groups of goldfish using independent sample $t$-tests showed a significant increase of $\mathrm{R}$ values and a significant decrease of $B$ values at second sampling (Table 2).

\section{DISCUSSION}

Data of the growth rate and feed conversion calculated for the whole experimental period indicate that $6.4 \%(\mathrm{~m} / \mathrm{m})$ paprika addition negatively affects feed consumption of koi carp. This phenomenon was not observed in the case of goldfish.
Table 2 Changes of RGB graycale values in goldfish

\begin{tabular}{lcccccr}
\hline & & \multicolumn{2}{c}{ Control } & & \multicolumn{2}{c}{ Paprika } \\
\cline { 3 - 4 } \cline { 7 - 7 } Sampling & RGB & Mean & SD & & Mean & SD \\
\hline 1 & R & $195.5^{\mathrm{a}}$ & 12.6 & & 197.7 & 9.5 \\
& $\mathrm{G}$ & 91.1 & 12.2 & & 90.8 & 13.7 \\
& $\mathrm{~B}$ & 30.4 & 14.7 & & $31.5^{\mathrm{a}}$ & 12.8 \\
& $\mathrm{R}$ & $173.5^{\mathrm{b} *}$ & 10.1 & & $204.4^{*}$ & 13.0 \\
& $\mathrm{G}$ & 98.6 & 18.0 & & 84.0 & 15.4 \\
& $\mathrm{~B}$ & $35.2^{*}$ & 15.1 & & $5.4^{\mathrm{b} *}$ & 5.1
\end{tabular}

$n=10$ randomly chosen fish per experimental unit.

$\mathrm{R}$, red; G, green; B, blue (grayscale values).

${ }^{*} P<0.05$ (control vs paprika, $t$-test); ${ }^{\mathrm{a}, \mathrm{b}, \mathrm{c}} \mathrm{P}<0.05$ (comparison of RGB means of samplings using ANOVA).

The RGB values seem to play different roles in the development of the visible 'redness' of the two species. In most of the cases the B values decreased continuously in artificial keeping and feeding conditions and the paprika as a carotenoid feed additive seems to have no effect on this process. The $G$ values remain unchanged or decreased slightly as redness increased due to paprika feeding. The $\mathrm{R}$ values had a tendency to increase due to paprika feeding but significant differences can be expected only after 4 weeks at the feeding rate and carotenoid concentration we applied. Both the initial rate of redness and genetic background are thought to influence the rate of red color intensity change, which could explain the differences between the two studied fish species. Our results are in accordance with Morimoto et al. ${ }^{4}$ and Tsushima et al., ${ }^{3}$ proving the efficacy of paprika as a feed additive in goldfish and koi carp.

The RGB values are proposed to be used for earlier detection of diet effect or fine phenotypic differences in future investigations. Significant improvement is needed for following the development of colors and a precise differentiation of color intensity and patterns within and between varieties in both species is essential. The methodology used in these experiments can serve as a promising base for testing the genetic potential of coloration. Because our software was proved to be applicable in the measurement of further characteristics (e.g. shape and distribution of patterns) of ornamental koi carp, it is planned to be applied in studies on the inheritance of these characteristics.

\section{REFERENCES}

1. Simpson KL. Use of carotenoids in fish feeds. In: Proceedings of World Symposium on Finfish Nutrition and Feed Technology, Hamburg, 20-23 June 1978, Volume 11. Heinemann, Berlin. XXX; 415-424. 
2. Katayama T, Shintani K, Chichester CO. The biosynthesis of astaxanthin. Comp. Biochem. Physiol. 1973; 448: 253-257.

3. Tsushima M, Nemoto H, Matsuno T. The accumulation of pigments from paprika in the integument of goldfish Carassius auratus. Fish. Sci. 1999; 64: 656-657.

4. Morimoto T, Amano T, Okamoto M. XXX. In: Takeda M, Watanabe $\mathrm{T}$ (eds). Proceedings of the Third International
Symposium on Feeding and Nutrition In Fish, 28 August-1 September, Toba, Japan 1989; 379-385.

5. Taniguchi N, Kijima A, Tamura T, Takegami K, Yamasaki I. Color, growth and maturation in ploidy-manipulated fancy carp. Aquaculture 1986; 57: 321-328.

6. Gonzales RC, Wintz P. Digital Image Processing. AddisonWesley, Reading, Massachusetts. 1987. 
Fisheries Science

Volume 69, 2003

BSA article no: 740

\section{AUTHOR QUERY FORM}

\section{Dear Author}

During the preparation of your manuscript, the questions listed below have arisen. Please answer all the queries (marking any other corrections on the proof enclosed) and return this form with your proofs.

\begin{tabular}{|l|l|l|}
\hline $\begin{array}{l}\text { Query } \\
\text { no. }\end{array}$ & Query & Reply \\
\hline 1 & Au: please provide year of publication. & \\
\hline 2 & Au: please provide title of paper. & \\
\hline
\end{tabular}

